\title{
Cognitive and affective assessment in day care versus institutionalized elderly patients: a I-year longitudinal study
}

This article was published in the following Dove Press journal:

Clinical Interventions in Aging

5 June 2014

Number of times this article has been viewed

\author{
Ana Maseda \\ Aránzazu Balo \\ Laura Lorenzo-López \\ Leire Lodeiro-Fernández \\ José Luis Rodríguez-Villamil \\ José Carlos Millán-Calenti \\ Gerontology Research Group, Faculty \\ of Health Sciences, University of A \\ Coruña, A Coruña, Spain
}

Correspondence: José Carlos Millán-Calenti Gerontology Research Group, Department of Medicine, Faculty of Health Sciences, University of A Coruña, Campus de Oza, 15006, A Coruña, Spain

Tel $+3498 । \quad 167000$ extension 5865

Fax $+3498 । \quad 167 \quad 120$

Email jcmillan@udc.es
Purpose: Cognitive decline and depression are two common mental health problems that may create a need for long-term care among the elderly. In the last decade, the percentage of older adults who receive health care in nursing homes, day care centers, or home support services has increased in Europe. The objectives of this descriptive and nonrandomized longitudinal study were to evaluate and to compare the cognitive and affective evolution of day care versus institutionalized older patients through a 1-year period, and to assess the presence of cognitive and affective impairment as a function of the care setting.

Patients and methods: Ninety-four patients were assessed at baseline, and $63(67.0 \%)$ were reassessed 1 year later. Neuropsychological assessment included measures of cognitive performance (general cognitive status, visuospatial, and language abilities) and affective status (depressive symptoms).

Results: Our findings indicated that the majority of the participants (day care and institutionalized patients) had mild-moderate cognitive impairment at baseline, which significantly increased in both groups after 1-year follow-up. However, the rate of change in global cognitive function did not significantly differ between groups over time. Regarding language abilities, naming function maintained among day care patients in comparison with institutionalized patients, who showed worse performance at follow-up. As regards to affective status, results revealed that institutionalized patients had a significant reduction in depressive symptoms at follow-up, when compared to day care patients. Results also highlight the high frequency of cognitive impairment and depressive symptoms regardless of the care setting.

Conclusion: Our findings revealed a similar global cognitive decline rate between patients receiving day care services and those residing in a nursing home at the 1-year follow-up, and slightly different trajectories in other outcomes such as naming function and depressive symptoms.

Keywords: cognitive and affective assessment, day care elderly patients, institutionalized patients

\section{Introduction}

A high prevalence of cognitive and affective declines among the elderly has been reported in previous cross-sectional studies. Cognitive impairment has been shown to affect $22.2 \%$ of the elderly population, ${ }^{1}$ and a large proportion of cognitively impaired older adults present coexisting depressive symptoms. ${ }^{2,3}$ The relationship between cognitive status and depressive symptoms and their liability to cause functional decline is of clinical and public health relevance, as it appears to be common, frequently coexists, and may be treatable. ${ }^{3}$ Cognitively impaired and/or depressed older adults are likely to experience different degrees of physical impairment and/or chronic diseases, and 
serious functional limitations on basic and/or instrumental daily activities, which may create health care needs. ${ }^{4}$

Nursing homes services serve heterogeneous older adults with varying degrees of physical and cognitive impairment and/or chronic illness, which create a need for assistance with basic or instrumental activities of daily living. Dementia patients are often placed in a nursing home, usually after using day care services. These day care services, which were originally developed to reduce the caregiver burden, have been shown to be effective in maintaining the cognitive function of dementia patients and in improving their behavioral and psychological symptoms, ${ }^{5}$ being considered an alternative to institutionalization or nursing home care.

It has also been demonstrated that utilizing communitybased long-term care services earlier in the dementia caregiving career delays time to nursing home placement or institutionalization. ${ }^{6}$ In general, day care services are preferred by many older adults and enhance their quality of life. Previous studies have identified the main predictors of institutionalization, including low frequency of socializing with relatives and friends, higher number of psychiatric diagnoses, worse cognitive performance, and increased age. ${ }^{7}$ It has also been found that the risk of nursing home placement increases significantly with the number of days of day care attendance, with this effect being substantially greater for men than for women. ${ }^{8}$

The number of longitudinal studies comparing different settings of care and describing changes in health/cognitive outcomes over time is limited, and the results are mixed. ${ }^{9}$ In this sense, although a considerable body of literature separately describes institutionalized and noninstitutionalized elderly populations, few studies directly compare the two. In this context, longitudinal studies can provide a better understanding of the progression from normal aging to the initial stages of dementia, and they can help to draw conclusions about how the care setting influences cognitive and affective functions in older adults. However, literature on the topic is difficult to compare due to the heterogeneity of care services, populations, and measures.

Based on previous investigations, we hypothesize that cognitive and affective changes - with time - may differ between day care and institutionalized groups. The present investigation consisted of a 1-year longitudinal study that aimed to evaluate the characteristics and the cognitive and affective evolution of day care versus institutionalized older patients. We were also interested in assessing the presence of cognitive and affective disorders in these groups, and in evaluating the impact of the setting of care (day care or nursing home care) on the cognitive and affective performance of patients.

\section{Materials and methods Subjects}

Our study covered patients $\geq 65$ years of age admitted to the Gerontological Complex La Milagrosa, sited in A Coruña (Spain). The complex consists of a day care center and a nursing home. We selected all residents of both care settings ( $\mathrm{n}=99 ; 59$ day care patients and 40 nursing home residents), and then we evaluated the 94 who agreed to participate. Core services provided by the day care center include small-group training on memory, activities of daily living, reality orientation, and cognitive stimulation. Nursing home services additionally offer a 24-hour room, supervision, and nursing care (personal care, medication management and administration, palliative care, rehabilitation, activities, and transportation). Also, 56 day care patients and 38 permanent institutionalized patients were assessed at baseline. In addition, 31 of the 94 participants screened at baseline dropped out during the 12-month study period, with 12 individuals having withdrawn from the institution, eight reported being too ill to participate, and eleven died. Figure 1 shows the flowchart of the participants. Also, 1 year after the first assessment, the $63(67.0 \%)$ subjects who remained in the study were reassessed (40 day care patients and 23 institutionalized patients).

The study was approved by the Ethics Committee of the University of A Coruña and was in conformity with the principles embodied in the World Medical Association's Declaration of Helsinki. All subjects were informed in advance about the study and gave their consent to participate in the study, either directly or through their legal representatives.

\section{Cognitive and affective assessment}

General cognitive status assessment

The cognitive status was assessed by a qualified clinical psychologist using the Mini-Mental State Examination

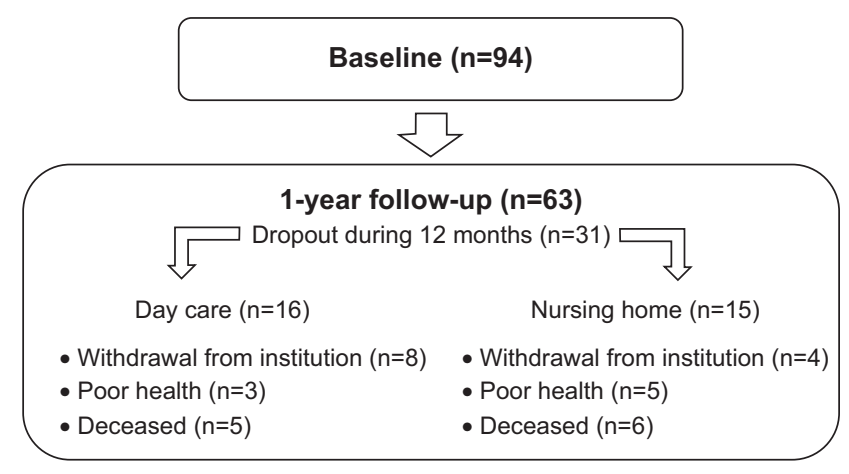

Figure I Participants' dropout rates and reasons. 
(MMSE), ${ }^{10,11}$ which examines several areas of cognitive function: orientation; memory; attention; language; and praxis. MMSE scores, ranging from 0-30, were adjusted for age and the level of education, ${ }^{11}$ being 24/25 the recommended cut-off (nondemented above 24). The Alzheimer's Disease Assessment Scale-cognitive subscale (ADAS$\operatorname{cog})^{12,13}$ was also administrated, with a total range of $0-70$ (a higher score indicating a more impaired cognition).

As MMSE or ADAS-cog could not always be considered due to the cognitive impairment of the participants (MMSE scores $\leq 10$ ), we used the Test for Severe Impairment (TSI), ${ }^{14}$ which has been shown to be a valid measure to cognitive changes over time in severely demented patients. Finally, the Reisberg's Global Deterioration Scale (GDS) ${ }^{15}$ was administrated for staging dementia in different settings. GDS describes seven stages of cognitive function from 1 (no subjective complaints of memory deficit) to 7 (very severe cognitive impairment).

\section{Visuospatial attention assessment}

Regarding visuospatial attention, form A of the Trail Making Test (TMT-A) ${ }^{16}$ was administrated. This instrument provides information on visual search, scanning, speed of processing, mental flexibility, and executive functions. ${ }^{17,18}$ It requires participants to draw lines sequentially, connecting 25 encircled numbers distributed on a sheet of paper. Scoring was based on the time required to complete the task (higher scores indicating greater cognitive impairment).

\section{Language assessment}

The specific instruments selected to evaluate language function were: the Verbal Fluency Test (VFT) ${ }^{19,20}$ to specifically assess fluency, and the short form of the Boston Naming Test $(\mathrm{BNT})^{21}$ to assess confrontation-naming performance. Regarding fluency, the 1-minute semantic verbal fluency test for the "animals" category was applied to all participants by a speech therapist. They were asked to evoke as many different animals as they could, over a time period of 60 seconds. The total number of correct and nonrepeated animals listed was recorded. Lower scores indicated greater cognitive impairment; the cut-off for impairment has been established as $<10$ points. ${ }^{22}$ Regarding the BNT, participants were asked to name the presented pictures (a set of line drawings of 15 common objects), and they were allowed approximately 20 seconds to name each drawing. If the correct word was not produced in that time, a phonemic cue was given, and an additional period of 20 seconds was allowed for a response.

\section{Affective assessment}

Depressive symptoms were evaluated by a psychologist using the Geriatric Depression Scale in its shorter form (GDS-sf), ${ }^{23}$ a questionnaire specifically developed for screening depressive symptoms in elderly populations. We specifically administered a Spanish-validated version of the test adapted for patients $>65$ years, ${ }^{24}$ which recommends using a cut-off point of 5 or above to consider the existence of probable clinical depression.

\section{Data analysis}

All statistical analyses were performed using the PASW Statistics 18 statistical package version 18.0.0 (SPSS Inc., Chicago, IL, USA). ${ }^{25}$ The level of significance was defined as $P<0.05$. The sample's characteristics were analyzed using descriptive statistics and frequency distributions. The day care recipients and nursing home residents' characteristics were then compared at baseline and follow-up by means of the Student's $t$-test for independent samples. In addition, the Student's paired $t$-test was used to compare the cognitive and affective scores between the two assessments points for each group.

To explore the clinical importance of significant differences, effect sizes were computed as Cohen's $d$ (small $d=0.20$; medium $d=0.50$; large $d=0.80),{ }^{26}$ with a positive effect size representing an improvement and a negative effect size representing a worsening of scores.

\section{Results}

\section{Sample characteristics}

Sociodemographic characteristics of the final study sample $(n=63)$ are described in Table 1 as a function of care services. As can be seen in Table 1, there was a significant difference between the day care and institutionalized patients with regard to age $(P<0.012)$. The institutionalized patients were older than the day care patients (day care, $81.85 \pm 7.56$ years; institutionalized, 86.43 \pm 4.91 years). However, there was no significant difference between groups with regard to education $(P=0.401)$. Of the 40 day care patients, $25.0 \%$ were illiterate or had no formal education, while $75.0 \%$ had primary to university education. Of the 23 institutionalized patients, $13.0 \%$ had no formal education, and $87.0 \%$ had primary to university education.

Regarding the dropout rates, an independent $t$-test revealed no significant differences on the baseline characteristics of completers $(n=63)$ and noncompleters $(n=31)$, revealing that age at baseline, sex, level of education, and care setting did not differ between the completers 
Table I Characteristics of final study groups

\begin{tabular}{|c|c|c|c|c|}
\hline Variable & $\begin{array}{l}\text { Day care patients } \\
(n=40)\end{array}$ & $\begin{array}{l}\text { Institutionalized } \\
\text { patients }(n=23)\end{array}$ & $t(d f)$ & $P$-value \\
\hline Mean age $\pm S D$ (years) & $81.85 \pm 7.56$ & $86.43 \pm 4.91$ & $-2.605(6 \mathrm{I})$ & $0.012 *$ \\
\hline \multicolumn{5}{|l|}{ Sex } \\
\hline Female, n (\%) & $31(77.5 \%)$ & 17 (73.9\%) & & \\
\hline Male, n (\%) & $9(22.5 \%)$ & $6(26.1 \%)$ & & \\
\hline Education & & & $-0.846(6 \mathrm{I})$ & $0.40 \mathrm{I}$ \\
\hline Illiterate, n (\%) & I (2.5\%) & - & & \\
\hline No formal education, but can read, $\mathrm{n}(\%)$ & $9(22.5 \%)$ & $3(13.0 \%)$ & & \\
\hline Primary school, n (\%) & $24(60.0 \%)$ & $16(69.6 \%)$ & & \\
\hline Secondary school, n (\%) & $3(7.5 \%)$ & $2(8.7 \%)$ & & \\
\hline University, n (\%) & $3(7.5 \%)$ & $2(8.7 \%)$ & & \\
\hline
\end{tabular}

Notes: Significant values are in bold; $* P<0.05$.

Abbreviations: SD, standard deviation; $d f$, degrees of freedom.

and those who discontinued the study (age $[P=0.765$, completers: $83.52 \pm 7.03$ years, range 65-97; non-completers: $83.10 \pm 5.16$ years, range 68-94], level of education $[P=0.096]$, sex $[P=0.590$, completers: 15 males, 48 females; non-completers: nine males, 22 females], and care-setting $[P=0.275$, completers: 40 day-care patients, 23 nursing home residents; non-completers: 16 day-care patients, 15 nursing home residents]). These results indicate that the dropout rate was not related to baseline characteristics.

\section{Descriptive analysis and intergroup differences at baseline and follow-up}

The descriptive analysis and intergroup comparison at baseline and at follow-up are reported in Table 2.

Cognitive impairment (MMSE score <24) was present in $77.5 \%$ of the day care patients and in $82.6 \%$ of the institutionalized patients at baseline. Notably, as can be seen in Table 2, both groups showed comparable baseline cognitive impairment as assessed by mean MMSE total scores after correcting for age and education level (day-care: 18.55 \pm 5.84 ,

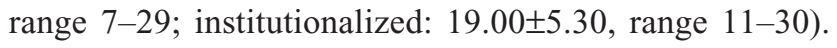
At follow-up, cognitive impairment was present in $90.0 \%$ of the day care patients and in $78.3 \%$ of the institutionalized patients. Again, both groups showed comparable global cognitive impairment at follow-up (day-care: 17.20 \pm 5.63 , range 5-28; institutionalized: 17.52 \pm 6.40 , range 9-30). Thus, with regard to the MMSE scores, day care patients were not statistically different to institutionalized patients at both assessment points. In the same line, groups did not differ with regard to ADAS-cog and TSI scores.

Regarding GDS staging, $20.0 \%$ of the day care patients showed very mild cognitive decline (GDS2), 25.0\% showed mild cognitive decline (GDS3), 30.0\% showed moderate cognitive decline (GDS4), and 25.0\% showed moderately severe cognitive decline at baseline. For the institutionalized patients, $4.3 \%$ of them showed no cognitive decline (GDS1), $13.0 \%$ showed very mild cognitive decline (GDS2), 30.5\% showed mild cognitive decline (GDS3), 30.5\% showed moderate cognitive decline (GDS4), and 21.7\% showed moderately severe cognitive decline. As can be seen in Table 2, no significant differences between the groups were observed at baseline as assessed by mean scores on the

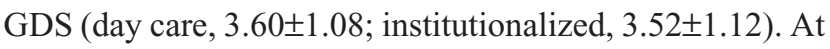
follow-up, $5.0 \%$ of the day care patients showed very mild cognitive decline (GDS2), 30.0\% showed mild cognitive decline (GDS3), 42.5\% showed moderate cognitive decline (GDS4), 20.0\% showed moderately severe cognitive decline (GDS5), and 2.5\% showed severe cognitive decline (GDS6). For the institutionalized patients, $4.3 \%$ of them showed no cognitive decline (GDS1), 17.4\% showed very mild cognitive decline (GDS2), 4.3\% showed mild cognitive decline (GDS3), 39.2\% showed moderate cognitive decline (GDS4), and $34.8 \%$ showed moderately severe cognitive decline (GDS5). Results revealed no significant intergroup differences in mean GDS scores at follow-up (day care, 3.85 \pm 0.89 ; institutionalized, 3.83 \pm 1.23 ).

As can be seen in Table 2, regarding visuospatial function, the group of institutionalized patients showed better performance on the TMT when compared to day care patients at follow-up $(P<0.044)$. The clinical significance of this difference was high $(d=0.85)$, and it was not observed at baseline assessment $(P=0.190)$.

Regarding language function, the patients showed comparable verbal impairment as assessed by their mean scores on the VFT and BNT. In fact, there were no significant differences in the number of evoked animals in the VFT, or in the number of spontaneous naming responses in the BNT, both at baseline and follow-up.

As regards affective status, depressive symptoms (GDS-sf scores $\geq 5$ ) were present in: $31.6 \%$ of the day care 


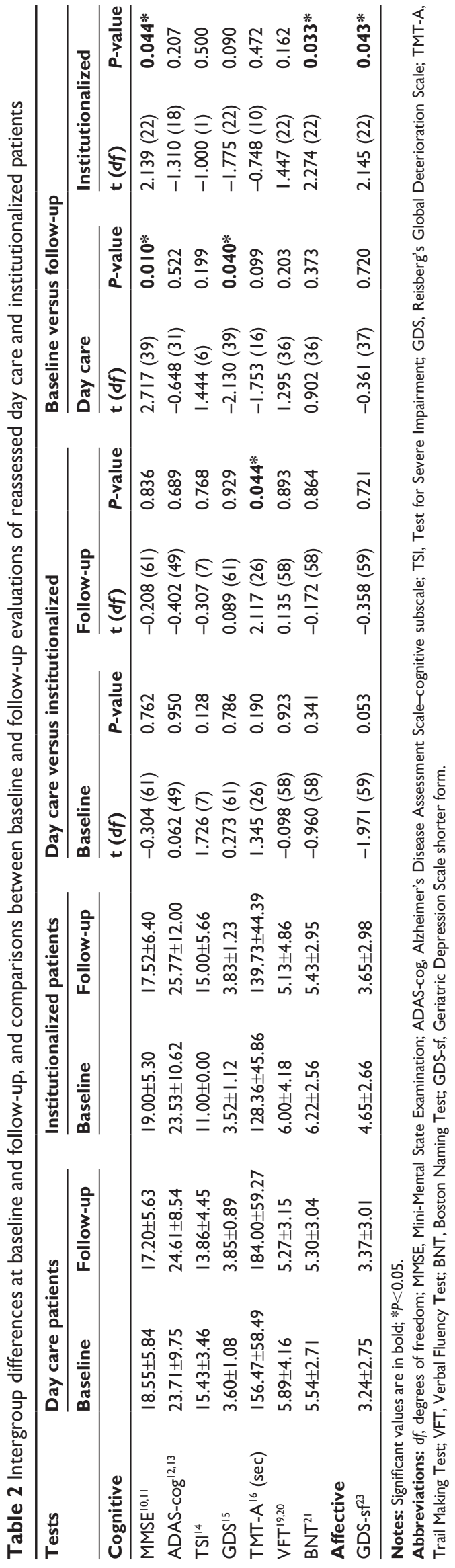

patients and in $34.8 \%$ of the institutionalized patients at baseline; and in $34.2 \%$ of the day care patients and in $30.4 \%$ of the institutionalized patients at follow-up. No statistically significant intergroup difference was observed considering the two assessment points.

\section{Baseline versus I-year follow-up comparison}

Mean scores of test measures at baseline and after a 1-year period were calculated and compared for day care and institutionalized patients. The evolution of clinical variables between baseline and the 1-year assessment is reported in Table 2 for day care and institutionalized reassessed patients.

Regarding trajectories of global cognitive decline, a significant decrease on follow-up mean MMSE total scores, compared to baseline, revealed a cognitive deterioration for both day care ( -1.35 points; $P<0.010 ; d=-0.43)$ and institutionalized ( -1.48 points; $P<0.044 ; d=-0.45$ ) reassessed patients; the clinical importance of the deterioration was relatively low in both groups.

Mean ADAS-cog and TSI total scores were unaffected between baseline and follow-up, in both groups. However, the tendency was toward cognitive decline. A significant increase on follow-up GDS scores was also observed in day care patients $(P<0.040 ; d=0.34$, low clinical significance), but not in institutionalized patients $(P=0.090)$.

Regarding visuospatial abilities, mean TMT-A scores were unaffected between baseline and follow-up, both in day care and institutionalized patients.

Concerning language function, verbal fluency scores were unaffected between baseline and follow-up in both care settings. Results also suggested that the naming abilities did not significantly decrease for day care patients. However, after 1 year, there was a significant - although relatively little clinically important - decline in BNT scores for institutionalized patients $(P<0.033 ; d=-0.47)$. As can be seen in Table 2 , these patients exhibited poorer naming scores at follow-up (decline from 6.22-5.43 between the two assessment points).

About affective status, comparisons results revealed that institutionalized patients had a significant reduction of depression mean scores at follow-up $(P<0.043, d=-0.45$, relatively), compared to day care patients, the clinical importance of the change being relatively low.

\section{Discussion}

This paper assessed and compared the short-term evolution of the cognitive and affective status of day care and institutionalized patients at 1-year follow-up, and the presence of 
cognitive and affective disorders as a function of the type of care services.

Efficient comparisons of cognitive and affective outcomes between these care services can be difficult due to patients' heterogeneity, both within and across settings. In fact, older adults who need care services may present different degrees of physical and cognitive impairment and may require different levels of assistance with daily living tasks. In this line, previous studies have shown that nursing home residents are more physically and cognitively impaired than those residing in residential care/assisted living facilities. ${ }^{27}$ A recent study revealed the beneficial effects of cognitive stimulation in long-term care institutions, this effect being significantly higher in institutionalized patients compared to noninstitutionalized patients. ${ }^{28}$

In the present study, we have based the measurement of cognitive impairment presence on the MMSE scores, which have been previously used to evaluate the rate of cognitive deterioration and predict institutionalization and mortality. ${ }^{29}$ Cognitive decline has been considered an important predictor for functional dependence, being a useful tool indicating the need for support. ${ }^{3}$ Our results indicated that the percentage of cognitive impairment at baseline was $77.5 \%$ for the day care patients and $82.6 \%$ for the nursing home residents. Thus, a majority of patients in both groups showed cognitive impairment at inclusion. These findings highlight the high frequency of cognitive impairment in both day care and institutionalized older patients. At follow-up, cognitive impairment frequency was also high, being present in $90.0 \%$ of the day care patients and in $78.3 \%$ of the institutionalized patients. However, no statistically significant differences between the groups were observed considering the two assessment points (baseline and follow-up).

Regarding baseline versus follow-up comparison, a significant decrease in MMSE performance was observed, regardless of the type of care service after 1 year. In this sense, normal older adults are expected to remain more cognitively stable for a long period, possibly losing fewer points per year. In this line, in a 3-year longitudinal study evaluating the cognitive evolution of community-dwelling older adults without dementia, the cognitive mean decline over the 3 years was 0.7 points. ${ }^{30}$ In dementia patients, the MMSE decline is usually more rapid and aggressive, with averages of annual decline of $2-3$ points. ${ }^{31}$ Thus, the progression of cognitive decline observed in our study can be considered slow or intermediate, regardless of care setting (1.35 points in day care patients and 1.48 in institutionalized patients).
ADAS-cog has also been considered an efficacy measure to study the rate of cognitive deterioration. In our study, ADAS-cog total scores were unaffected between baseline and follow-up. However, there was a tendency toward cognitive decline in both groups, according to the MMSE results previously discussed. Concerning TSI scores, no significant changes were observed after 1 year. As regard to GDS staging, results revealed a decrease in the mean score of day care patients, but not in the mean scores of institutionalized patients.

Taking into account all the cognitive status measures employed, our findings indicate that the rate of change in cognitive function did not significantly differ between institutionalized and semi-institutionalized patients over time. This result is in line with previous longitudinal studies showing that people living in the two care settings did not change at different rates. ${ }^{27,32}$ However, other studies have reported that nursing home placement is associated with an increase in the rate of cognitive decline, ${ }^{33}$ this association being reduced when high level use of day care services precedes the institutionalization. ${ }^{5}$ It has also been observed that slower long-term cognitive decline is associated with a higher cognitive ability at baseline or a lower level of education in Alzheimer's patients. ${ }^{34}$

It is important to note that day care and institutionalized patients did not significantly differ in terms of education in our study but did differ by age, with the average institutionalized patients being almost 5 years older than the day care patients. Thus, a potential limitation of this study was the lack of statistical adjustment for age despite this difference. However, despite both groups not being matched in age at baseline, the cognitive decline rate was similar regardless of care setting.

Regarding visuospatial function, the group of institutionalized patients showed better performance on the TMT-A than day care patients at follow-up, but not at baseline. However, the baseline versus follow-up comparison revealed that TMT-A scores were unaffected between the two time points regardless of care setting, indicating that visuospatial attention function was maintained over time. It is important to note that the scores were lower than expected, ${ }^{35}$ suggesting deficits in cognitive processing speed and executive function.

About language abilities, it is important to note that the verbal fluency and the denomination function were affected in both day care and institutionalized patients at baseline. However, there were no significant differences between the groups. In fact, participants showed comparable verbal impairment with no significant differences in the number of 
evoked animals, or in the number of spontaneous naming responses both at baseline and follow-up. About the baseline versus follow-up comparison, participants did not show a significant decrease in the VFT after 1 year, regardless of the care service. This test evaluates semantic memory and has been considered a screening test on its own for cognitive impairment and dementia. ${ }^{22}$ As regards to BNT scores, our results indicate that naming abilities maintained unchanged after 1 year for day care patients but significantly decreased for institutionalized patients, who exhibited poorer capacity of naming the objects. This is relevant, since naming is one of the most important abilities in linguistic processing, involving different cognitive operations, such as visuoperceptual, semantic, lexical, and articulatory processes.

Finally, in our study, depressive symptoms were widely observed regardless of the care setting, affecting $31.6 \%$ of the day care patients and $34.8 \%$ of the institutionalized patients at baseline, and $34.8 \%$ of the day care patients and $30.4 \%$ of the institutionalized patients at follow-up. In previous studies, the prevalence of depressive symptoms varies depending on the studied population, affecting up to $17.3 \%$ of older community dwellers ${ }^{3}$ and up to $26.6 \%$ of institutionalized older adults. ${ }^{36}$ It has been reported that the depression prevalence rates among nursing home residents are up to three to four times higher than in communitydwelling elderly, ${ }^{37}$ and that the risk factors of depression observed in nursing homes are similar to those in the community. ${ }^{38}$ Regarding baseline versus follow-up comparison, results revealed that the level of depression significantly decreased in institutionalized patients during follow-up. In previous studies, the results regarding affective change have been mixed, with some studies finding more depressive symptoms in institutionalized patients, ${ }^{33}$ and others in noninstitutionalized patients over time. ${ }^{39}$ Other studies did not find statistically significant difference in rates of changes in depressive symptoms. ${ }^{27-32}$ The reduction of depressive symptoms observed in our study may be related to the natural process of adaptation to institutionalization or to the more specialized supervision and nursing care from professionals, who adequately and individually address depressive symptoms in nursing homes.

To sum up, our findings revealed a similar global cognitive decline rate regardless of care setting, and slightly and minimally clinically important different trajectories in other outcomes, such as naming function and presence of depressive symptoms. The results from this study should be viewed in the context of methodological limitations that may have implications for causal inferences. The sample size was relatively small and not randomized; there was a high rate of dropouts - as expected. Also, concomitant medication was not controlled.

\section{Conclusion}

In general, we failed to demonstrate a different cognitive evolution in day care and institutionalized patients with a similar initial level of cognitive deterioration at inclusion. In this context, the difference in setting (day care versus nursing home) likely reflects other factors, such as the availability and affordability of nursing homes, or the availability of informal support for day care patients.

\section{Author contributions}

AM participated in the study, supervised the data collection, was responsible for the statistical design and for carrying out the statistical analyses, interpreted the results, and drafted the paper. LLL participated in the study, assisted in the analysis and interpretation of the data, and critically revised the manuscript. JLRV participated in the selection of participants and administration of GDS. AB collected data on cognitive status. LLF collected data on language function. JCMC designed the study and critically revised the manuscript. All authors read and approved the final manuscript.

\section{Acknowledgments}

We wish to thank all the patients and their relatives for their cooperation in the study. The authors are grateful to the staff at both the day care center and the nursing home at the Gerontological Complex La Milagrosa, who took part in the management of the patients and provided administrative support during the study.

\section{Disclosure}

The authors report no conflicts of interest in this work.

\section{References}

1. Millán-Calenti JC, Tubío J, Pita-Fernández S, González-Abraldes I, Lorenzo T, Maseda A. Prevalence of cognitive impairment: effects of level of education, age, sex and associated factors. Dement Geriatr Cogn Disord. 2009;28(5):455-460.

2. Reifler BV, Larson E, Hanley R. Coexistence of cognitive impairment and depression in geriatric outpatients. Am J Psychiatry. 1982;139(5): 623-626.

3. Millán-Calenti JC, Tubío J, Pita-Fernández S, Rochette S, Lorenzo T, Maseda A. Cognitive impairment as predictor of functional dependence in an elderly sample. Arch Gerontol Geriatr. 2012;54(1):197-201.

4. Millán-Calenti JC, Maseda A, Rochette S, Vázquez GA, Sánchez A, Lorenzo T. Mental and psychological conditions, medical comorbidity and functional limitation: differential associations in older adults with cognitive impairment, depressive symptoms and co-existence of both. Int J Geriatr Psychiatry. 2011;26(10):1071-1079. 
5. Wilson RS, McCann JJ, Li Y, Aggarwal NT, Gilley DW, Evans DA. Nursing home placement, day care use, and cognitive decline in Alzheimer's disease. Am J Psychiatry. 2007;164(6):910-915.

6. Gaugler JE, Kane RL, Kane RA, Newcomer R. Early community-based service utilization and its effects on institutionalization in dementia caregiving. Gerontologist. 2005;45(2):177-185.

7. Cohen-Mansfield J, Wirtz PW. Characteristics of adult day care participants who enter a nursing home. Psychol Aging. 2007;22(2):354-360.

8. McCann JJ, Hebert LE, Li Y, et al. The effect of adult day care services on time to nursing home placement in older adults with Alzheimer's disease. Gerontologist. 2005;45(6):754-763.

9. Wysocki A, Butler M, Kane RL, Kane RA, Shippee T, Sainfort F. Long-Term Care for Older Adults: A Review of Home and CommunityBased Services Versus Institutional Care. Comparative Effectiveness Review, Number 81; 2012. Available from: http://effectivehealthcare.ahrq.gov/ehc/products/369/1276/CER81_Long-Term-Care_ ExecutiveSummary_20121023.pdf. Accessed February 4, 2014.

10. Folstein MF, Folstein SE, McHugh PR. "Mini-mental state". A practical method for grading the cognitive state of patients for the clinician. J Psychiatr Res. 1975;12(3):189-198.

11. Blesa R, Pujol M, Aguilar M, et al; NORMACODEM Group. NORMAlisation of Cognitive and Functional Instruments for DEMentia. Clinical validity of the 'mini-mental state' for Spanish speaking communities. Neuropsychologia. 2001;39(11):1150-1157.

12. Rosen WG, Mohs RC, Davis KL. A new rating scale for Alzheimer's disease. Am J Psychiatry. 1984;141(11):1356-1364.

13. Peña-Casanova J, Aguilar M, Santacruz P, et al. [Adaptation and normalization of the Alzheimer's disease Assessment Scale for Spain (NORMACODEM) (II)]. Neurologia. 1997;12(2):69-77. Spanish [with English abstract].

14. Albert M, Cohen C. The Test for Severe Impairment: an instrument for the assessment of patients with severe cognitive dysfunction. $J \mathrm{Am}$ Geriatr Soc. 1992;40(5):449-453.

15. Reisberg B, Ferris SH, de Leon MJ, Crook T. Global Deterioration Scale (GDS). Psychopharmacol Bull. 1988;24(4):661-663.

16. Reitan RM. Validity of the Trail Making Test as an indication of organic brain damage. Percept Mot Skills. 1958;8(3):271-276.

17. Mitrushina MN, Boone KB, Razani J, D'Elia LF. Handbook of Normative Data for Neuropsychological Assessment. 2nd ed. New York: Oxford University Press; 2005.

18. Tombaugh TN. Trail Making Test A and B: normative data stratified by age and education. Arch Clin Neuropsychol. 2004;19(2):203-214.

19. Strauss E, Sherman EMS, Spreen O. A Compendium of Neuropsychological Tests: Administration, Norms, and Commentary. 4th ed. New York: Oxford University Press; 2006.

20. Benito-Cuadrado MM, Esteba-Castillo S, Böhm P, Cejudo-Bolívar J, Peña-Casanova J. Semantic verbal fluency of animals: a normative and predictive study in a Spanish population. J Clin Exp Neuropsychol. 2002;24(8):1117-1122.

21. Kaplan E, Goodglass H, Weintraub S. Test de Vocabulario de Boston [Boston naming test]. In: Goodglass H, Kaplan E, García Albea J, editors. Evaluación de la afasia y de los trastornos relacionados [Aphasia assessment and related disorders]. Madrid: Médica Panamericana; 2005:A3.1-A3.9.

22. Carnero-Pardo C, Lendínez-González A. Utilidad del test de fluencia verbal semántica en el diagnóstico de demencia. [The utility of the semantic verbal fluency test in diagnosis of dementia]. Rev Neurol. 1999;29(8):709-714. Spanish
23. Yesavage JA, Sheikh JI. 9/Geriatric Depression Scale (GDS) Recent Evidence and Development of a Shorter Version. Clin Gerontol. 1986; 5(1-2):165-173.

24. Martínez de la Iglesia J, Onís Vilches MC, Dueñas Herrero R, Albert Colomer C, Aguado Taberné C, Luque-Luque R. Versión española del cuestionario de Yesavage abreviado (GDS) para el despistaje de depresión en mayores de 65 años: adaptación y validación. [The Spanish version of the Yesavage abbreviated questionnaire (GDS) to screen depressive dysfunctions in patients older than 65 years]. MEDIFAM. 2002;12(10):620-630. Spanish [with English abstract].

25. SPSS Inc. PASW Statistics 18 Core System User's Guide. Chicago: SPSS; 2009. Available from: http://www.unt.edu/rss/class/Jon/SPSS_ SC/Manuals/v18/PASW\%20Statistics\%2018\%20Core\%20System $\% 20$ User\%27s\%20Guide.pdf. Accessed January 16, 2014.

26. Cohen J. A power primer. Psychol Bull. 1992;112(1):155-159.

27. Sloane PD, Zimmerman S, Gruber-Baldini AL, Hebel JR, Magaziner J, Konrad TR. Health and functional outcomes and health care utilization of persons with dementia in residential care and assisted living facilities: comparison with nursing homes. Gerontologist. 2005;45 Spec No 1(1): 124-132.

28. De Oliveira TC, Soares FC, De Macedo LD, Diniz DL, Bento-Torres NV, Picanço-Diniz CW. Beneficial effects of multisensory and cognitive stimulation on age-related cognitive decline in long-term-care institutions. Clin Interv Aging. 2014;9:309-320.

29. St John PD, Montgomery PR, Kristjansson B, McDowell I. Cognitive scores, even within the normal range, predict death and institutionalization. Age Ageing. 2002;31(5):373-378.

30. Pereira CPM, Stella F, Hernandez SSS, Andrade LP, Texeira CVL, Gobbi S. Longitudinal cognitive screening study in community-dwelling individuals. Dement Neuropsychol. 2010;4(3):214-221.

31. Gauthier S, Vellas B, Farlow M, Burn D. Aggressive course of disease in dementia. Alzheimers Dement. 2006;2(3):210-217.

32. Pruchno RA, Rose MS. The effect of long-term care environments on health outcomes. Gerontologist. 2000;40(4):422-428.

33. Marek KD, Popejoy L, Petroski G, Mehr D, Rantz M, Lin WC. Clinical outcomes of aging in place. Nurs Res. 2005;54(3):202-211.

34. Wattmo C, Wallin AK, Londos E, Minthon L. Predictors of long-term cognitive outcome in Alzheimer's disease. Alzheimers Res Ther. 2011;3(4):23.

35. Ashendorf L, Jefferson AL, O'Connor MK, Chaisson C, Green RC, Stern RA. Trail Making Test errors in normal aging, mild cognitive impairment, and dementia. Arch Clin Neuropsychol. 2008;23(2):129-137.

36. Gruber-Baldini AL, Zimmerman S, Boustani M, Watson LC, Williams CS, Reed PS. Characteristics associated with depression in long-term care residents with dementia. Gerontologist. 2005;45 Spec No 1(1):50-55.

37. Jongenelis K, Pot AM, Eisses AM, Beekman AT, Kluiter H, Ribbe MW. Prevalence and risk indicators of depression in elderly nursing home patients: the AGED study. $J$ Affect Disorders. 2004;83(2-3): 135-142.

38. Eisses AM, Kluiter H, Jongenelis K, Pot AM, Beekman AT, Ormel J. Risk indicators of depression in residential homes. Int J Geriatr Psychiatry. 2004;19(7):634-640.

39. Edelman P, Fulton BR, Kuhn D, Chang CH. A comparison of three methods of measuring dementia-specific quality of life: perspectives of residents, staff, and observers. Gerontologist. 2005;45 Spec No 1(1): 27-36.
Clinical Interventions in Aging

\section{Publish your work in this journal}

Clinical Interventions in Aging is an international, peer-reviewed journal focusing on evidence-based reports on the value or lack thereof of treatments intended to prevent or delay the onset of maladaptive correlates of aging in human beings. This journal is indexed on PubMed Central, MedLine,

\section{Dovepress}

CAS, Scopus and the Elsevier Bibliographic databases. The manuscript management system is completely online and includes a very quick and fair peer-review system, which is all easy to use. Visit http://www.dovepress. com/testimonials.php to read real quotes from published authors. 